\title{
Creative English: balancing creative and functional language needs for adult refugees, asylum seekers and migrants
}

\author{
Anne Smith
}

\begin{abstract}
This article argues that play and creativity are cornerstones of a personcentred approach to adult second language education. However, when learners are refugees, asylum seekers or migrants already living in the country where the language is spoken, it is important that language learning also addresses their functional needs. Creative English is an applied theatre programme for adults in the UK that balances these functional and creative needs while developing confidence in English language communication skills. Drawing on participant-led, practice-based research which resulted in the development of Creative English, this article purports the benefits of an approach that combines playful emotional engagement with pragmatic subject matter. Creative English is based on improvisation. It reduces inhibitions and creates a state highly conducive to learning and taking the risk to communicate in a second language. It also offers the opportunity to rehearse language in everyday life situations. When learners' perceived needs are met, Maslow's hierarchy of needs can then be inverted, as creativity allows opportunity to address needs in terms of self-esteem and belonging.
\end{abstract}

\section{Introduction}

At the start of the $21^{\text {st }}$ century, the number of migrants into the UK attracted a disproportionate level of public concern (Duffy \& Frere-Smith 2014). Public anxiety has been enflamed by negative representations of migrants in the media (Moore et al. 2012). Keen to respond decisively to these perceptions, UK government policy has increasingly limited opportunities for migrants, which make it difficult for them to achieve a sense of belonging (Kesete et al. 2015).

Refugees may also have experienced torture or other extreme suffering, and the dislocation and powerlessness created by migration itself means high levels of mental health issues that remain prevalent amongst all migrants in comparison with the host population (Tidyman et al. 2004: 26). The ability to access services and a community of friendship and support is integral to 
well-being and cannot be achieved in the UK without being able to speak the English language, which is the first step towards functional and then emotional integration. Research conducted by the Refugee Council and the University of Birmingham identified the ability to speak English as a key element in integration and a sense of belonging in the UK (Atfield et al. 2007: 7).

In 2006, NIACE found that English for Speakers of Other Languages (ESOL) provision was "critical to the success of a range of other key government policies, including the child poverty agenda, health, sustainable communities, regeneration, and community integration and cohesion" (ESOL Inquiry Executive Summary 2006: 5). Despite this report, funding for ESOL was removed in 2007, except for priority groups who were unemployed or receiving income-based benefits. This remaining funding has been steadily eroded. Despite the fact that 850,000 migrants self-reported on the 2011 census that they could not speak English well or at all, DEMOS identified a further 40\% reduction in ESOL funding between 2009 and 2014 (Paget 2014). There is an exigency, therefore, for holistic approaches which address well-being, as well as access to services, integration and functional language skills.

This article argues that impact on wider well-being is achieved through an applied theatre approach which emphasizes play, creativity and laughter, and that learning through playing is as valuable for adult refugees and migrants as it is for children. Thompson (2009) argues that most applied theatre projects take place within a framework of social utility, thus preventing the foregrounding of the pure joy they can bring, and the political importance of this type of intervention. The focus of funding on predetermined outcomes has resulted in "a certain atrophying of the practice, which now needs to be countered with, what I am calling attention to affect" (ibid. 117). Thompson defines "affect" as "the bodily sensation that is sustained and provoked particularly by aesthetic experiences. It is a force that emerges from attention to pleasure, astonishment, joy and beauty" (ibid. 135). Thus he argues for performances of beauty, which inspire happiness in the participants and claims that this part of their radical nature: "safety, protection and care (particularly when translated to situations of conflict) are not a retreat from some imagined politics of freedom, but the heart of its radical vision" (ibid. 118-9). He argues that:

[...] dancing, and other forms of aesthetic expression, might be places of respite, but the argument here suggests something more radical - they are also integral and necessary parts of change itself. In a world of inequality, social injustice and endemic violence, they could be acts of resistance and redistribution, made in an intimate and sensory key. (ibid. 11)

When forced migration, the inability to speak English and unfamiliarity with the culture and systems within the country of residence creates a feeling of powerlessness, an act of creative resistance and redistribution may be of particular importance. Thompson believes that affect lasts beyond the moment of performance. He encourages readers "to maintain their commitment to working with groups and communities in dynamic and joyful performance 
projects - and to continue to make real everyone's right to beautiful, radiant things" (ibid.). Creative English, an applied theatre initiative for adult refugees and migrants in the UK, foregrounds the importance of joy and playfulness for the wider well-being it can bring.

Examples from Creative English presented in this article were documented as part of three years of participant-led, practice-based research. The research involved 62 women across four different projects in East London, in mixed-ability groups ranging from beginners to Entry Level 2 (equivalent language skills of a 7-9 year-old). Some of the women were recent migrants, where others had lived in the UK for more than twenty years without learning English. Participants in each group came from a diverse range of countries including Afghanistan, Albania, Bangladesh, Democratic Republic of Congo, Ethiopia, India, Somalia, Poland and Turkey. During the initial 18 months of practice-based research, a variety of drama-based approaches were explored from functional role-play to purely creative and imaginative tasks. An ethnographic approach was adopted to workshop documentation. Participants were interviewed in their first language, or English, as desired, and commented on activities and their feelings of integration throughout the project. Feedback generated during this research shaped the development of what has become the main 'Creative English 38 week informal education programme,' delivered in faith and community settings across the UK, and a range of Creative English short courses with specific objectives, such as improved health literacy. The following section identifies learners' cultural expectations about learning that can result in skepticism towards learning through play and creativity, and explains how becoming aware of these barriers has shaped the approach of Creative English.

\section{Negotiating motivation and expectations}

All learners arrive at the workshop with preconceptions about what they need to learn and how best to do it. These preconceptions may come from previous learning experiences, peers or cultural backgrounds. As an informal education programme, Creative English engaged some of the most vulnerable learners, many of whom were illiterate in their first language, as well as those who may already have achieved an Entry-level 2 certificate in ESOL but lacked the confidence to speak much English elsewhere. Some learners used the sessions as an alternative to a formal ESOL course, with the clear objective to gain paid employment. Others simply hoped to be able to attend a doctor's appointment on their own, or to speak English with their grandchildren, who were the second generation born in the UK. To meet different learning styles and expectations, it is important to understand and address diverse motivations.

\subsection{Pre-conceptions of learning through play}

Much has been written about child-centred learning and how play is a core element of this approach (Tassoni \& Beith 2002; Doddington \& Hilton 2007; 
Entwistle 2012). However, this article argues that an emphasis on play should also be central to adult education, as it impacts on wider needs. Play has only comparatively recently been recognised by neuroscientists as a primary emotional function of the mammalian brain (Panksepp 1998: 281). Montagu (1998) argues that, in the Western world, there has "been a failure to recognise that the need to play remains a necessity throughout one's life, a biosocial necessity" [my emphasis]. He claims that the "four great chords of mental health are the ability to love, to work, to play and to think soundly," and that "it is remarkable how closely interwoven each of these abilities is with one another" (quoted in Blatner \& Blatner 1988: 7). Cohen (2006: 178) points out that adults frequently feel uncomfortable playing as they consider this something only a child should do. He argues that adults need to play more frequently and without feeling uneasy about it (ibid. 13).

The unease Cohen identifies with play as a legitimate learning medium, may be particularly prevalent for learners who have expectations of formal desk-based learning by rote derived from their country of origin. A British Pakistani ESOL tutor, who was trained in the UK but would not initiate or participate in play activities herself, explains:

"All they want to do is learn and function in their everyday lives and to a certain extent I always think the method of 'to play games' is very childish based ... It's as if it's aimed for children but for them, as adults at home, as mums who have children, it's got to be more of a constructive way of learning: sitting down and blackboard and books ... if you're aiming to cater for the different culture side we have and that's what the purpose of the classes are, it's got to work for them." (Interview with the author, No. 44)

While the notion of education rooted in "sitting down and blackboard and books" has long since disappeared from the British education system, this is not the case for most non-European participants. The active learning approach, popularised by Bonwell \& Eison in 1991, requires students to perform meaningful learning activities and to think about what they are doing, as opposed to passively receiving knowledge from a teacher or a textbook. While evidence from the practice-based research for Creative English showed that active learning through playing was very successful for adults, it was still necessary to make learners feel secure by addressing concerns about not learning enough, since a number of the participants in the practice-based research did express suspicion of active-learning techniques prior to engaging in the project. As a consequence, the learning objectives of play-focussed activities were made explicit, and opportunities to take notes or refer to photocopied worksheets were made available. Additionally, warm-up activities included explicit language-learning elements.

The necessity of highlighting the educational benefit even influenced the naming of the programme. Without a reference to English in the name, few adults are prepared to join an arts programme. For example, when the Refugee Arts Project sought to recruit adults for a theatre project in 2009, without 
an explicit reference to learning English, all the participants turned out to be between 13 and 20 years old and had previously been involved in school or youth theatre in the UK (Interview with the author, no. 54). The importance of including a reference to English language learning in the course title is reflected in other applied theatre projects such as Rewrite's 'Creative ESOL' and Richmond Theatre's 'Learning English through the Arts.' Abraham Maslow's theory of human motivation helps to explain the necessity for this emphasis, as the following section shows.

\subsection{Addressing motivation to attend}

The impact of a course name on attendance clearly suggests a prioritization of the language learning over arts in the minds of the learners. This preference is consonant with Maslow's theory of human motivation.

Maslow (1987) theorised human motivation to be dictated by a hierarchy of needs. According to the hierarchy, in the first instance, physiological needs have to be met, such as food and sleep. Safety needs, like health and employment, are the next priority, followed by love and belonging, then self-esteem, and finally self-actualisation, which is where creativity features. The need to be able to communicate in English when living in the UK is a fundamental safety need. If 'relative gratification' of a tier is not achieved, the thoughts and behaviour of an individual are completely dominated by this goal. The impact of this phenomenon is demonstrated beyond the field of applied theatre. The charity The Open Doors Project, for example, has tried to engage isolated refugees and migrants through activities such as keep-fit, card-making and 'Time Out for Women,' a course addressing social needs through health and beauty issues. In line with the hierarchy of need, the only activities that generated high levels of attendance are those marketed as addressing the safety need of improving English language skills. In accordance with Maslow's theory of motivation, interviews with participants with English of Entry Level 2 standard or below clearly expressed a preference for drama activities which improved their English in functional situations, despite enjoying the purely creative drama work.

Awareness of participants' need to develop competence in functional language prompted drama activities which addressed everyday events. At first the results were disappointing: the atmosphere was flat and the language used was unnecessarily simple and stilted. Aristotle identified conflict as integral to the very nature of drama. Without conflict, everyday situations do not make interesting drama, as there is not enough tension (Fleming 1998: 151). Exploration of creating tension through problem-solving in a form such as Forum Theatre (where audience members are invited to intervene in a scenario in role as the protagonist to try to change the outcome) was beyond the linguistic comprehension of many members of the group. The introduction of a family of archetypal characters finally provided the necessary tension. The plotline for this family and their neighbours evolved through the sessions, engaging with everyday situations but also involving humour and melodrama, similar 
to a soap opera. A visit from a long-lost brother, for example, provided a context for exploring practical language related to doctors, hospitals and blood tests, but also the emotional engagement of whether his family should forgive him a past betrayal. The combination of familiar characters and an episodic structure helped to support the learning of those who were unable to attend regularly, which is characteristic of more vulnerable learners. The structure gave participants freedom to shape outcomes of the storyline while also maintaining the facilitator's ability to supply the appropriate realia and costumes to support the understanding of the least able in the mixed-ability session. Props and costumes also increased the sense of having permission to play as adults, especially when involving artefacts characterized by some element of exaggeration, such as colourful wigs and toddler puppets.

According to Maslow's definition, 'relative gratification' implies that needs have to some extent been met in each tier before progressing to the next level. However, if this were the case, applied theatre work in contexts such as refugee camps and homeless shelters, where unresolved physiological and safety needs remain, would remain unattended unless participants were coerced. Refugees and vulnerable migrants may have quite extreme and long-term physiological and safety needs, owing to experiences in their country of origin or within the UK. Despite the relative safety of the UK, exposure to hostility from an unwelcoming host community, enflamed by the rise of Islamophobia post 9/11, and the uncertainty generated by the asylum process and its outcomes may result in significant physical and psychological issues (Tidyman et al. 2004; Palmer \& Ward 2006; Moore et al. 2008). In the context of long-term physical and emotional challenges, I argue that 'relative gratification' may be acceptance rather than resolution of the current need or circumstance. If there is no immediate possibility of remedying one's homelessness, illness or safety, the choice to participate in a creative project may be an empowering and liberating one, refusing to be defined by restrictions of personal circumstance.

Although 'relative gratification,' when defined as acceptance of existing needs may release participants into an arts project as a source of joy and resistance, this will not apply at the moment of crisis itself when a fundamental physiological or safety need becomes known. Having built relationships with others within the creative project, a lack of access to other sources of help may also mean that participants attend, even at the moment of crisis. On attending, however, their concentration will not be on the arts activities. Moreover, if their situation is not resolved by the next session, this may be their last appearance, as the importance of this need dominates their thoughts. For this reason, partnerships and links with other organisations are very important, as they can fulfil practical needs and offer specialist advice. In one session, for example, a Congolese participant arrived at a workshop distraught because she had just become homeless, and could not focus on drama activities. What was more beneficial was to introduce her to someone from the partner charity, Lifeline Projects, who could help her access emergency accommodation and support her in negotiating the application process for further financial assistance. The following week, 
crisis overcome, she was back participating in the drama sessions with full enthusiasm. This woman described the Creative English group as her "spiritual family," recognising the value of having what another participant described as "friends for help not just for fun" within the group. Where practical support for basic needs was being provided by Lifeline Projects and The Open Doors Project, the aesthetic experience of the Creative English sessions simultaneously enabled the emotional need for friends and provided a sense of belonging. While Maslow's theory of human motivation explains why learners engage with the sessions, playful aesthetic experience actually allows these needs to be met in the reverse order.

\section{Play and creativity meeting the language 'safety' need}

According to Maslow, creativity involves "here-now self-forgetfulness and otherforgetfulness" (1971: 67). He lists the attributes of this 'forgetful' state as: "less fear, less inhibition, less need for defence and self-protection, less guardedness, less need for artificiality, less fear of ridicule, of humiliation and of failure" (ibid.). Less fear and inhibition is highly beneficial when learning to speak a second language. Despite Maslow's association between creativity and the highest tier of self-actualisation, creative improvised tasks provide an opportunity to address the fundamental 'safety need' of the ability to communicate in line with Krashen's theory of adult second language acquisition.

\subsection{Building confidence in speaking in English}

Krashen (1981: 1) argues that adult second language acquisition is very similar to the process that children go through when learning language for the first time:

[...] it requires meaningful interaction in the target language - natural communication - in which speakers are concerned not only with the form of their utterances but with the messages they are conveying and understanding."

Krashen (2003: 4) renamed this theory the Comprehension Hypothesis to emphasize the role played by understanding in acquisition. Drama provides a context in which meaningful communication takes place; there is something to be achieved by listening, understanding, and responding. It is, therefore, an ideal way to facilitate language acquisition.

Kao (1994) and Wilburn (1992) conducted studies which found that the language produced in drama is more authentic and close to that of a native speaker than language produced in other traditional classroom oral activities (Kao and O'Neill 1998: 59). However, when Kao analysed improvisation transcripts, it became apparent that "compared with their fluency, the accuracy of the students' language use did not appear to be that impressive" (ibid. 63). The study focused on first year university students in Taiwan who were a 
much more educated participant group than those participating in the Creative English research: the majority of whom only had a primary school or no formal education and were at an early stage of learning English. In Creative English, one would therefore expect this characteristic to be further exaggerated. As in everyday life, Kao found that the inaccuracies did not seem to affect the development of the drama, as the context helped make the meaning clear to the participants. As in real-life communication, there was an emphasis in Creative English on building confidence through communicating and understanding the gist, rather than every word.

Unlike the traditional role-play of the language classroom, physical engagement in improvisation forces participants to draw on and experiment with the language they are learning. In a Creative English improvised scene, police refused to allow a Queen to pass through a police cordon. While one of the police actors spoke little English and was reluctant to speak, she could gesture her denial of entry to the Queen. However, the Queen and her entourage were determined. "No come," the policewoman articulated adamantly, as her attempts to shoo away the visitors failed. As an aid to language learning, this repeated pressure to respond in an improvised scene is one of its strengths, as it forces participants to explore previously untested solutions to the situation they face. Active participation forces learners to draw on what they already know and to push themselves to be more specific. In the traditional classroom, there is plenty of time for learners to sit quietly. If they are disengaged from the process, they are not learning from it. Being passive when presented with a second language simply does not result in language being retained, as research into the extent people learn language from watching television shows (Garza 1991: 239; Bravo 2008 193). Output promotes more 'noticing' (Swain 1995: 100). In producing the target language, learners may notice differences between their output and either ask questions to clarify when they are receptive to learn or self-correct. In rehearsal for the above scene, for example, the woman playing the Queen initially said, "I want go." She then corrected herself, "I want to go?" Encouraged by a nod from the facilitator, she then used the correct preposition in her performance to the rest of the class.

Despite the grammatical imperfection of the other performer's "No come", the combination of word, tone and gesture provided the reluctant speaker with the confidence boost of communicating the desired meaning, which could be transferred into their next attempt to speak. The ability to communicate was far more important than technical language accuracy. This illustrates the relative value of 'Focus on Meaning' over 'Focus on Form' for the Creative English research participants. 'Focus on Form' is based on the assumption that learners' accuracy improves when grammar taught as it arises within communicative language practice (Long 1991). Long (1996: 451) suggests that negotiating meaning, especially negotiation that triggers interactional adjustments by the native or more competent speaker, facilitates acquisition. This is because it connects input, internal learner capacities (especially selective attention), and output in productive ways. Piazzoli (2011: 560) argues that process drama can generate 
Long's focus on form while actually balancing negotiation of meaning with fluency and accuracy. Whilst agreeing with this view, I argue that for beginners and low-level English speakers, focus on meaning is of primary importance in building confidence and fostering a sense of belonging. Piazzoli's students were third-year university students learning a foreign language. Their immediate goals and prior experience of the language were therefore very different to the women participating in Creative English in an informal, community learning context. Rather than language competence in an academic context, these learners want to be able to go shopping, make a complaint, talk to teachers, seek help from doctors, and chat to neighbours in their street. Fluency, not accuracy, is therefore their primary and most pressing goal.

\subsection{The impact of engaging the emotions}

Participation and the desire to communicate about personal experience releases language. In drama, this occurs both within improvisations and when reflecting on experiences afterwards, particularly when emotions were touched. In improvisation, the trigger may be empathy with a particular character or situation. An improvisation retelling the Greek legend of Persephone provides an example. A previously quiet, middle-aged Turkish woman released a torrent of language at her character's husband, who had not yet attempted to recover their daughter from Hades:

"So find my daughter. Why aren't you doing anything, yeah? All you do is sit there. You don't do nothing. What are you waiting for? Go find her. Don't sit on your big fat arse. Get my daughter. I miss her. You don't do nothing. You don't know what is happening to her. She is with bad man. Why you still sit there? You are lazy husband. Bring her back to me! Safe! Go, now!"

Her character's distress at losing her daughter and her frustration at her husband's apathy connected with her emotions; this enabled her to express herself with an eloquence neither she nor the rest of the group expected. As a speechless Zeus sloped off the stage, the woman laughed with surprise at her own outburst and authority. Her emphasis took the plot on to a whole new dimension, as Zeus became a weak character, too lazy to act without the passionate insistence of his wife. Her unexpected eloquence gave the woman a new confidence in her capacity to speak that impacted upon future interactions outside the session. According to her teacher, this included her willingness to speak in the formal ESOL sessions that she was attending.

The ability to play roles of different status also has a value to participants. One participant explained how she felt "empowered": "It's like feeling you could be somebody and saying things that you wouldn't say normally, as you're being a different version of you." According to Blatner (1988: 38), people get tired, bored or burnt out when restricted to certain dominant roles: 
Excessive or prolonged enactment of authoritative, submissive, controlling, competent, helping, helpless, or any other general type of role generates a type of psychic fatigue. It is a relief to engage in an activity that embodies a role that contrasts with a previously extensively enacted role.

Recent migrants need to break out of patterns of behaviour associated with struggling to survive. Refugees are constantly prescribed the role of victim by both society and the way they are represented in art, which foregrounds passive vulnerability and experience of trauma. They thus benefit psychologically from transcending what Jeffers (2008: 219) describes as "demonstrations of victimhood." The mental release of alternative roles not only explores alternative possibilities which may be enacted in their lives but also helps them to cope better mentally with their current reality. Blatner \& Blatner (1988: 38) argue that playful adoption of a variety of roles is psychologically beneficial: "To balance your roles, through actively expressing them generates an experience of wholeness in your psychological existence that nourishes and heals your psyche." For the usually timid woman playing the Queen, the improvisation where she overcame the police allowed a joyful subversion of her usual self-expectations. Despite having expressed a fear of police in real life, triumph over them in the fictional context energised and refreshed her, causing her to leave the session with a spring in her step, chatting animatedly. The apparently frivolous 'playing' in role with a sparkly plastic crown and blond wig could challenge the sense of powerlessness generated by an inability to communicate. This freedom in fictional social roles and exploration of language in a variety of contexts could open up other possibilities in real life. As one participant explained: "After these lessons I start studying at Redbridge Institute, Adult Education, and if I didn't come maybe [to the Creative English class at] Lifeline Centre maybe I didn't feel confident to make test in Institute" (Interview with the author, no. 12). Confidence and possibility generated in fiction can have a definite impact in life.

\subsection{Spontaneity and laughter generating transferable language}

Creative English sessions are characterized by laughter. Humour features within most of the plots within the sessions and the playful tone encourages light-hearted exploration of the topics. For one research participant, this was her imperative for attending: "I have to come," she said. "This is the only place I laugh."

A playful approach aided memory on serious topics. One session, for example, dealt with how to contact the emergency services. Within the session, a story was improvised that involved the wife spotting smoke coming from a neighbour's house and calling the fire brigade. As a warm-up activity, various tableaux were responded to with improvised phone calls to the emergency services. The atmosphere was light-hearted. Another session included making a report to the police about a snatched bag. In contrast to a Redbridge conversation class on this theme, which magnified the fear of crime and encouraged participants not to go out in the dark, there was again laughter, as the would-be thief sprinted 
around the room in a desperate attempt to evade capture. Many weeks later, one of the participants became separated from her three-year-old while shopping. Despite having arrived in the UK only recently, she was able to phone the police and get them to recover her child, who had got onto a bus travelling away from home. The mother firmly related her ability to cope with the situation to her participation in the drama session:

"I was worried but I remembered what to do. I rang the police and the police came and they sorted everything out and we were together again and that was only because I knew what to do. Your session taught me that." (Interview with the author no. 15)

Even though the drama-rehearsed language was for different specific situations, she was able to transfer the knowledge she had gained, even under pressure, to be able to solve the problem she faced. Improvisation equips people particularly well in this way. Exploration of a serious subject through play creates a relaxed context where more language is likely to be absorbed and be available for use in other situations. Opportunities to play maintains both creativity and flexibility which enhance the ability to solve problems and improves resilience, as enjoyment is experienced as well as relentless challenge. Brown (2009: 71) argues that

[...] if we stop playing, we share the fate of all animals that grow out of play. Our behaviour becomes fixed. We are not interested in new and different things. We find fewer opportunities to take pleasure in the world around us.

The difficulties many of the research participants had faced had destroyed their time/inclination to play, which in turn made life more difficult for them. The opportunity to reconnect with a sense of play and joy in the sessions makes it easier to respond creatively to problems faced. It also enhances the ability to build positive relationships with people from different backgrounds, as the following section explores.

\section{Play and creativity addressing self-esteem}

When everyday life is imbued with risk and challenges in ordinary situations, play can be an invaluable source of well-being. Furukawa \& Hunt (2011: 199) highlight that many immigrants experience shame as a consequence of appearing incompetent because of their limited language skills, lack of education or job skills, or unfamiliarity with the host country's cultural practices. The inability to negotiate even simple tasks like shopping, using public transport, or helping their children with homework erodes self-esteem. These situations threaten their role as parents, providers and protectors and can lead to feelings of worthlessness. By contrast, play and creativity generate safe spaces in which one can be uninhibited. In play, there is no right or wrong. All participants 
are equal, regardless of language competence. Play dismantles the usual social hierarchy.

The methodology used within the practice-based research projects encompassed a range of art forms and drama activities that did not rely on the spoken word. Consequently, all participants were able to play, create, and contribute fully, regardless of language skills. An example from a Creative English short course, where the object was to write a children's story, illustrates how needs are met through the arts in the opposite sequence to Maslow's hierarchy. A Pakistani woman in the group spoke no English and struggled to learn, owing to her lack of previous schooling and illiteracy in her own language. When interviewed in Urdu about the sessions, she simply stated: "I enjoy your classes. I like you but unfortunately I don't understand" (Interview with the author no. 16). However, the use of puppets in the session enabled her to understand and communicate more effectively than her peers. During a session where participants were sharing traditional stories from their countries, the use of animal puppets and props enabled her to recognise a fable that was being shared. She then instigated the retelling of a fable she remembered. In her operation of the main character, a crow puppet, she created a huge amount of mirth. No words were needed but she introduced some well-timed comic squawks from the squeaker in the puppet's beak. The class roared with laughter and the woman's eyes shone. She positively glowed with delight as she took centre stage in the group in a way she had never been able to before. Her sense of humour and ability to entertain the group won her admiration from the rest of the class, which in turn gave her more confidence. After making little progress in her spoken English, her language skills now began to improve significantly, as she took more risks in speaking out and interacting with others. As she built better relationships with others in the group, she gained more opportunities to practice English outside the sessions. In this example, the woman was motivated to attend by the 'safety' need to learn English in accordance with Maslow's hierarchy. However, in addressing her needs, the hierarchy was completely upturned. It was the creative activity, which gave her the self-esteem to build relationships, and it is these relationships that then supported her in improving her English language skills. Although not evidenced within this research project, it is conceivable that, having improved basic language skills or had other safety needs met, this may allow a participant to achieve the physiological needs of Maslow's base tier. Without the framing of the context to learn English however, this learner would not have attended the creative session in the first place.

\section{Play and creativity as a generator of belonging}

As identified in the Introduction, Thompson (2009) expresses the value of participation in an arts project in times of need. Despite Creative English's focus on language necessary for functional interactions, its power lies in the joy and playfulness of the encompassing character's storylines. The characters not only create a protective distance for learners where they are not obliged to 
represent themselves but also provide common ground. Relationships within fictional families create empathy across cultures due to shared characteristics, roles and values. The playful tone and shared character creation process removes strong identification with particular cultural traditions. As an example: In a session which had the functional language goal of empowering learners to access Children's Centres, Rebecca meets volunteer Tom. In subsequent sessions, participants often enjoyed developing a romance between these two characters. In the role of Rebecca's family, participants utilized a variety of question structures, motivated by a genuine desire to assess the character's suitability as a partner: "Do you have money?" "How will you behave with wife?" "Why are you not married now?" This often resulted in women with arranged marriages themselves approving the 'love match.' Despite the preconceived outline of the session, the outcomes for the characters were not prescribed so, in one group, Tom's character could actually turn out to be hapless and unpleasant. His disrespectful attitude towards his girlfriend's parents made the group cry with laughter, as he described his career goal as being to sit on the sofa and watch television. The participants have ownership over the material, which motivated them to practice functional language. However, it is the joyfulness of the shared experience which compelled all members of the group to engage. The shared emotion created a temporary feeling of communitas, a sense of solidarity even with strangers. Although the moment of spontaneous communitas may be short-lived, it enables what Turner describes as 'normative communitas' to develop. Spontaneous communitas has something "magical" about it when individuals "become totally absorbed into a single synchronized, fluid event", where status is abolished, and all are equal (Turner 1982: 47f). When status is temporarily removed, a particularly exhilarating sense of belonging can temporarily occur. Turner defines the paradox of communitas as being that the "experience of communitas" becomes the "memory of communitas." In striving to replicate itself, communitas then historically develops a social structure, "in which initially free and innovative relationships between individuals are converted into norm-governed relationships between social personae" (ibid. 47). It is in this context that one finds normative communitas. Normative communitas is "a subculture or group which attempts to foster and maintain relationships of spontaneous communitas on a more or less permanent basis" (ibid. 49). Moments of spontaneous communitas can exist within the normative and it is these moments that continue to bind existing relationships and help to draw new members into a place of belonging in the group. Creative English, as developed in its original model, allows participants to join the group at any point. The themes within the sessions are self-contained, with continuity provided by familiar characters in each episode of the plot. The structure accommodates the erratic attendance typical of the most vulnerable, due to illness, childcare and appointments with professionals. Moments of spontaneous communitas help to bind the group, whether one has attended many times before or whether this is one's first week. These moments of spontaneous communitas can be so compelling that those on the fringes want to join in. One participant explained 
how she had become involved: "I'd never heard such guffaws of laughter. I had to keep sticking my head out of the door [from an office elsewhere in the venue] to see what was going on." In this way, the applied theatre workshop space can become a liminal space where a sense of community emerges within the group and moments of spontaneous communitas are a catalyst for normative communitas to occur.

\section{Conclusion}

Exploring functional needs through play and creativity does so much more for learners than addressing their language skills. It breaks through their isolation, creates a sense of belonging and impacts upon their well-being. Aesthetic experiences are not dependent on the hierarchy of need having been fulfilled. Moreover, they can in fact contribute to the gratification of these needs, reversing the sequence. Creativity may build self-esteem, which in turn may facilitate making friends and achieving a sense of belonging, which in turn allows safety needs to be addressed. A programme such as Creative English supports adults by providing a context to experience the benefits of play, while also addressing functional needs through generating confidence in the language they need in order to function holistically within their communities. Fun and laughter is integral to making this a success. However, while this programme succeeds in its objective to increase confidence in speaking English, the improvement in accuracy demanded by higher level speakers is not addressed. Therefore, for those requiring higher level language skills, this programme may be more effective as a bridge into other sources of language provision or as a programme parallel to more formal learning opportunities, to increase confidence in using what has been learnt. For many isolated learners, Creative English may be the only context where they meet with supportive English speakers. While the educational and psychological benefits of this way of working are clearly recognized in this article, the positioning of the project within the wider context of the organization is important if an aesthetic experience is to facilitate safety and physiological needs. Strong partnerships are essential with other agencies who can support participants, if necessary, in meeting basic needs.

\section{Bibliography}

Atfield, Gaby; Brahmbhatt, Kavita \& O’Toole, Therese (2007): Refugees Experiences of Integration. London: Refugee Council

Blatner, Adam \& Blatner, Allee (1988): The Art of Play: An adult's guide to reclaiming imagination and spontaneity. New York: Human Sciences Press

Bonwell, Charles C. \& Eison, James A. (1991): Active Learning: Creating Excitement in the Classroom. ASHE-ERIC Higher Education Report No. 1, Washington, DC: George Washington University 
Bravo, Maria Da Coceiao Condinho (2008): Putting the Reader in the Picture: Screen Translation and Foreign Language Learning. Universitat Rovira I Virgili, Spain.www.teisienxarxa.net/TESIS_URV/AVAILABLE/TDX0123109-134524/Condhino.pdf [last accessed October 4, 2010]

Brown, Stuart (2009): Play: How it Shapes the Brain, Opens the Imagination and Invigorates the Soul. New York: Penguin Group

Cohen, David (2006): The Development of Play. Hove, East Sussex: Routledge

Doddington, Christine \& Hilton, Mary (2007): Child-Centred Education: Reviving the Creative Tradition. London: Sage

Dodson, Sarah L. (2002) The Educational Potential of Drama in ESL. In: Bräuer, Gerd (ed.): Body and Language. Westport: Ablex Publishing, 161-178

Duffy, Bobby \& Frere-Smith, Tom (2014): Perceptions and Reality: Public Attitudes to Immigration. London: Ipsos MORI Social Research Institute

Entwistle, Harold (2012): Child-Centred Education. Abingdon, Oxon: Routledge

ESOL Inquiry Executive Summary (2006): NIACE. www.niace.org.uk/projects/esol-enquiry/documents/ESOL-InquiryExecutiveSummary .pdf [last accessed May 20, 2007]

Fleming, Mike (1998): Cultural Awareness and Dramatic Art Forms. In: Byram, Michael \& Fleming, Mike (eds.): Language Learning in Intercultural Perspective. Cambridge: Cambridge University Press, 147-157

Furukawa, Emi \& Hunt, Dennis J. (2011): Therapy with Refugees and Other Immigrants Experiencing Shame: A Multicultural Approach. In: Dearing, Ronda D. \& Tangney, June Price (eds.): Shame in the Therapy Hour. Washington: American Psychological Association 195-215

Garza, Thomas (1991): Evaluating the Use of Captioned Video Materials in Advanced Foreign Language Learning. In: Foreign Language Annals 24, 239-258

Hicks, David (n.d.): Person-centred Education. In Education and Ideology. n.d. www.teachingforabetterworld.co.uk/docs/Personcentred_Education.pdf [last accessed June 20, 2013]

Kao, Shin-Mei \& O’Neill, Cecily (1998): Words into Worlds. London: Ablex Publishing

Kesete, Nisan; Thom, Danielle \& Harvey, Heather (2015): Settling in. In: Experiences of Women on Spousal Visas in the UK. London: Eaves

Krashen, Stephen D. \& Terrell, Tracy D. (1983): The Natural Approach: Language Acquisition in the Classroom. Oxford: Pergamon Press

Krashen, Stephen (2003): Explorations in Language Acquisition and Use. Portsmouth: Heinemann

Long, Michael (1991) Focus on form: A design feature in language teaching methodology. In: De Bot, Kees; Ginsberg, Ralph \& Kramsch, Claire (eds.) Foreign Language Research in Cross-cultural Perspective. Amsterdam: John Benjamins 39-52 
Long, Michael (1996): The role of the linguistic environment in second language acquisition. In: Ritchie, William \& Bhatia, Tej (eds.): Handbook of Second Language Acquisition. San Diego, CA: Academic Press 413-468

Maslow, Abraham H. (2011): Toward a Psychology of Being. Blacksburg, VA: Wilder Publications

Maslow, Abraham H. (1987): Motivation and Personality. New York: Harper and Row

Maslow, Abraham H. (1971): The Farther Reaches of Human Nature. New York: The Viking Press

Moore, Kerry; Gross, Bernhard \& Threadgold, Terry (eds.) (2012): Migrations and the Media. Oxford: Peter Lang Ltd

Moore, Kerry; Mason, Paul \& Lewis, Justin (2008): Images of Islam in the UK: The Representation of British Muslims in National Print News Media 2000-2008. Cardiff: Cardiff School of Journalism, Media and Cultural Studies

Palmer, David \& Ward, Kim (2006): Unheard Voices: Listening to Refugees and Asylum Seekers in the Planning and Delivery of Mental Health Service Provision in London. London: Commission for Patient and Public Involvement in Health

Panayi, Panikos (1999): The Impact of Immigration. Manchester: Manchester University Press

Panksepp, Jaak (1998): Affective Neuroscience: the foundations of human and animal emotions. Oxford: Oxford University Press

Piazzoli, Erika (2011): Process drama: the use of affective space to reduce language anxiety in the additional language learning classroom. In: Research in Drama Education 16, 557-573

Sanderson, Helen (2000): Person-centred Planning: Key Features and Approaches. Joseph Rowntree Foundation.

www.familiesleadingplanning.co.uk/documenst/pcp\%20features\%20\&\%20styles.pdf [last accessed June 20, 2013]

Swain, Merrill (2000) The output hypothesis and beyond: Mediating acquisition through collaborative dialogue. In: Lantolf, James P.:

Sociocultural Theory and Second Language Learning. Oxford: Oxford University Press, 97-114

Tassoni, Penny \& Beith, Kate (2002): Child Care and Education. Oxford: Heinemann

Thompson, James (2009) Performance Affects: Applied Theatre and the End of Effect. Basingstoke: Palgrave Macmillan

Tidyman, Mary; Gale, Elizabeth \& Seymour, Linda (2004): Celebrating Our Cultures: Guidelines for Mental Health Promotion with Black and Minority Ethnic Communities. London: Department of Health

Turner, Victor (1982): From Ritual to Theatre: The Human Seriousness of Play. New York: PAJ Publications 
Verinder, Ben (2011): Association of Colleges ESOL Survey. In: Association of Colleges. www.aoc.co.uk/briefings/AoC_ESOL_Survey_February_2011.pdf [last accessed July 29, 2013] 